\title{
The Dopamine D4 Receptor Gene (DRD4) is Associated with Attentional Bias in Heroin Abusers and Cigarette Smokers
}

\author{
J. Lusher ${ }^{*}$, C. Chandler ${ }^{1}$ and D. Ball ${ }^{2}$ \\ ${ }^{I}$ Department of Psychology, London Metropolitan University, Old Castle Street, London, E1 7NT, UK \\ ${ }^{2}$ Social, Genetic and Developmental Psychiatry Research Centre, Institute of Psychiatry, Denmark Hill, London, SE5 \\ $8 A F, U K$
}

\begin{abstract}
The search for a genetic vulnerability gene for substance abuse has focused on dopaminergic genes, including the DRD4 receptor. In addition to clear biological mechanisms in substance abuse, many studies have found a psychological attentional bias to drug-related stimuli in substance users. This study aimed to determine whether a DRD4 gene polymorphism is associated with such attentional biases to substance-related stimuli. Eighty heroin abusers in treatment, 80 cigarette smokers, 80 alcohol abusers in treatment and 80 non-smoking community controls undertook an emotional Stroop task to measure attentional bias to drug-related stimuli. DNA was obtained from cheek cell samples and the DRD4 VNTR polymorphism genotyped. Heroin abusers and cigarette smokers, but not controls, who carried the long variant at the DRD4 gene spent significantly longer responding to drug-related stimuli than they did to neutral stimuli when compared to those who did not carry the long variant at the DRD4 gene. A non-significant trend to delay was observed in alcoholics. These findings suggest that variants at the DRD4 gene influence attentional bias in substance abusers and offer further insight into the role of the DRD4 gene in drug dependence as well as individual differences in the susceptibility to attentional bias to drug-related environmental cues.
\end{abstract}

\section{INTRODUCTION}

Recently there have been discussions concerning the dopamine D4 receptor gene (DRD4) VNTR polymorphism and its association with cue-reactivity in heavy drinkers [1]. The DRD4 VNTR polymorphism has also been examined in relation to cue-elicited craving in cigarette smokers [2]. However, this research has largely relied on self-report measures of attention to substance-related cues and has not considered cue-reactivity in abusers of illicit drugs, such as heroin, despite evidence of an association between the DRD4 gene polymorphism and heroin abuse [3].

The DRD4 gene is a logical candidate for attentional bias to substance-related cues because of its distribution in the brain. DRD4 receptors are dense in the nucleus accumbens (NAcc) and have been shown to be critical to sensitisation of NAcc pathways [4]. Nicotine has been shown to induce dopaminergic sensitisation in the NAcc [5]. Hutchison and colleagues [2] found that cigarette smokers with the long allele at the DRD4 gene showed an increase in craving and attention to drug cues during exposure to smoking-related stimuli, when compared to participants with the short allele, thus pointing to this polymorphism as a moderator in cuereactivity. Further work has supported this finding in a subsequent study with alcohol dependent participants [6], in which participants with the long alleles at DRD4 had an increase in alcohol craving after consuming alcoholic drinks

*Address correspondence to this author at the Department of Psychology, London Metropolitan University, City Campus, Calcutta House, Old Castle Street, London, E1 7NT, UK;T el: +44 (0) 207320 1282;

E-mail: j.lusher@londonmet.ac.uk compared to non-alcoholic drinks, illustrating the moderating effects of the DRD4 gene polymorphism on cue-elicited craving. This finding has support more recently in a study using 420 heroin users [7].

The way in which individual differences in genes influence attentional bias to substance-related cues is far from clear and there is currently limited evidence of the risk factors associated with enhanced drug-cue associative learning and responding. The physiological basis of drug taking has been said to occur due to distinct neural pathways, making up the mesolimbic dopamine system, that differ in response to novel, appetitive and aversive stimuli [8]. These genetically determined neural pathways are thought to allow for enhanced associative learning of drug effects, in particular in the NAcc $[9,10]$. An individual's susceptibility to conditioned responses to drug cues may develop powerful drugcue associations, therefore, producing greater cue reactivity.

There is currently a shortage of cue-reactivity research that has tested the attribution of incentive salience, although animal research suggests that the ability to induce sensitisation is modulated by learning and environmental cues [1114]. It appears that the interaction of neural sensitisation and associative learning is responsible for the focus that drug abusers have on drug-related stimuli. That is, the behaviours and objects associated with drug taking become powerful incentives themselves and the modulation of the expression of sensitisation via the drug-taking context may contribute to the crucial role that drug-related cues play in precipitating relapse.

Cue reactivity occurs when stimuli, such as environmental context or substance-related materials, become 
associated with the drug and due to this pairing become conditioned stimuli. Drug relevant stimuli become conditioned stimuli that elicit motivational states that can produce physiological and behavioural responses that are similar to that of the drug response [15]. This attentional bias can be tested using modifications of the Stroop task [16]. Modified Stroop tasks are especially useful for testing whether stimuli capture the attention of participants. In the original Stroop task participants were presented with lists of colour-words (e.g. RED), which were printed in different colours (e.g. blue). Participants were required to respond to the written word ("RED") whilst ignoring the colour in which the word was printed (blue) and name the colour ("blue") whilst ignoring the word (RED). Stroop found that to name the colour whilst ignoring the word produced longer response times [16]. The Stroop effect occurs because participants attention is directed partly toward the semantic properties of the stimuli (meaning of the word) and partly toward the perceptual properties (colour in which the word is printed). When the semantic and perceptual properties are inconsistent, interference occurs, thus producing longer respense times. differentiate between groups of individuals with and without a psychopathology, providing a reliable instrument for assessing attentional bias [17]. The emotional Stroop task uses stimuli that are either neutral in emotional valence or stimuli that are emotionally evocative for participants. The logic underlying the original Stroop can be extended to interpret results from emotional Stroop tasks. When participants are preoccupied with say alcohol and they encounter a word like "Vodka", they take longer to respond to the colour of that word than a neutral word like "Sofa" because extra time is taken to process the semantic properties of the associated stimulus.

Modifications of the Stroop test have been widespread and more recently, the Stroop paradigm has been used to investigate information processing biases underlying Substance Use Disorders (SUD). Gross and colleagues [18] measured the reaction times of smokers to smoking-related and neutral words. Successful performance of the Stroop task requires suppression of the meaning of the stimulus word in favour of activation of the colour name. Results were as predicted, abstinent smokers were slower to colour name smoking-related than non-smoking-related words. This finding has since been supported by further studies $[19,20]$ and further support for attentional bias can be seen in studies conducted with alcoholics [21-23]. This processing bias makes the suppression of meaning of substance-related words more difficult and leads to greater interference during the task.

Cue reactivity is an area where identifying and explaining individual factors that contribute to variability in drug sensitisation is of benefit because exposure to substancerelated stimuli in substance abusers could mediate the maintenance of their disorder by producing craving. This is because it makes the user want to use by being shown stimuli that remind them of the substance. The incentive sensitisation theory [24] claims that among individuals prone to substance dependence, the use of a substance sensitises their positive incentive value of the substance. Therefore the substance user becomes highly motivated to seek out drugs and related stimuli. The basis of substance dependence therefore is not the pleasure of taking the drug per se, but the anticipated pleasure of taking it. The wanting of the drug becomes sensitised and therefore the incentive salience of the drug becomes out of proportion with the pleasure obtained from it. Therefore, the drug is craved regardless of physical and social problems that are incurred from drug use.

It is apparent that individual differences contribute to drug-cue associative learning and responding. Therefore, using a modified emotional Stroop task, this study examined whether the DRD4 gene polymorphism influences the degree of attentional bias to substance-related environmental stimuli amongst users of different substances by comparing differences in stimuli-responsiveness between individuals with and without the long variant at the DRD4 gene.

\section{METHOD}

Three hundred and twenty unrelated, Caucasian individuals consented to take part in this study. Participation was entirely voluntary and no incentive was offered. The study was approved by London Metropolitan University; Maudsley and Bethlem Royal Hospitals NHS Trust; Croydon Local Research Ethics Committee and East London and City Health Authority in London UK. The sample comprised 80 opiate abusers in treatment (15\% female; mean age 36 years); 80 alcohol abusers in treatment (14\% female; mean age 41 years); 80 cigarette smokers ( $46 \%$ female; mean age 33 years) and 80 controls from general practice services ( $41 \%$ female; mean age 35 years). Mood disorders were self reported by $25 \%$ of the heroin group, $42 \%$ of alcoholics, $6 \%$ of smokers and $4 \%$ of controls. No other psychiatric disorder was reported in this sample. Ethnicity was an important factor in this study for genetic reasons. Ethnic differences in genes for complex disorders are to be expected since the allele frequencies vary widely [25]. Due to these differences between ethnic groups and to minimise confounding of genetic test results, inclusion criteria were met if participants were western European. Participant self-reports confirmed that smokers and controls were not in treatment for a SUD and controls did not smoke cigarettes, abuse illicit drugs or alcohol. Genetic data from $93.8 \%$ of the entire sample could be used for analyses. The 2-, 3-, 4-, 5-, 7- and 8-repeat alleles accounted for $9 \%, 2.3 \%, 77.3 \%, 0.18 \%, 11 \%$ and $0.18 \%$ of alleles, respectively. For the Stroop task, all participants were asked and stated that they had normal or corrected to normal vision and that English was their first language.

Participants were clean and sober at the time of the study. This was ensured as it was a requirement of the treatment service from within the local trust where heroin and alcohol groups were approached. Participants completed a series of questionnaires, provided a sample of their DNA using a cheek cell sample kit and carried out an emotional Stroop task on a laptop computer.

The Severity of Dependence Scale [26] was used to measure the degree of psychological dependence experienced by heroin users. A typical mean SDS score amongst a London population of heroin users is 8.7 (SD 4.0) [26]. The Severity of Alcohol Dependence Questionnaire (SADQ) [27] was administered to alcohol abusers. The higher the total score, the more severe the dependence syndrome, severely dependent individuals typically score 30 or above. The 
Questionnaire on Smoking Urges (QSU) [28] was administered to all participants who smoked cigarettes as a psychological measure of urges to smoke. Cigarette smokers smoked on average 14 cigarettes per day and had smoked cigarettes for an average of 16 years $(93 \%$ had smoked their last cigarette within the past week). $92 \%$ of both heroin and alcohol users had been abstinent for at least 24 hours. The heroin group had a mean severity of dependence score of 10.5 (SD 2.8) and the alcohol group had a mean severity of alcohol dependence score of 32.5 (SD 12.8).

The emotional Stroop task was delivered on a laptop computer and consisted of 144 trials grouped into three counterbalanced blocks of 48 trials. Words within their blocks were randomly shuffled by the modified emotional Stroop program. The words appeared on the screen in one of four different colours (red, blue, green or yellow) on a black background. Blocks and colours were randomized. Heroinrelated words were: heroin, chasing, foil, gear, bag, inject, methadone, smack. Alcohol-related words were: alcohol, booze, drunk, drink, hangover, pub, DTs, shakes, and smoking-related words were: cigarette, smoking, lungs, fags, lighter, nicotine, tobacco, ash tray. Response times to these stimuli were compared with that of neutral words: door, table, picture, sofa, chair, cabinet, rug, desk. This protocol was developed during piloting procedures carried out on a London population who were representative of the population approached for this study. During the piloting phase, participants were asked to list as many words as they could think of, which they would associate with their drug of choice. Dialect, language and slang vary from culture to culture, amongst different communities and from time to time, so by collecting words from a representative sample of the population to be recruited for the main study, it could be argued that the words were substance-related according to that particular population at the time the study was conducted. Stimuli were matched by length and number of syllables, rather than by frequency, because the time taken to read the words is what is measured during the task. Additionally, it has been argued that "the frequency with which participants who suffer from a particular disorder (e.g. alcohol abuse) have been exposed to words related to that disorder (e.g. alcohol-related words) is not represented by the frequency with which those words occur in the spoken language, leading researchers to question the relevance of the control" [p. 1263] [29]. Nevertheless, it is difficult to choose the correct method of matching stimuli [30] and choosing how to match words has given rise to lively discussion in the literature, without resolution. Household terms were used in the neutral condition as they belong to a category and therefore are semantically related to each other and are not closely associated to colour words, i.e. as sky is to blue [29]. The reaction time, error rate and total duration of task were recorded.

A practice Stroop task was performed whereby the participant's score appeared on the screen to determine error rate and to decide whether the participant could successfully go on to complete the main task. Participants were instructed to respond to the colour of the words, which appeared on the screen, whilst ignoring the content of the word. They were told to do this by pressing the appropriate coloured key on the keypad that corresponded with the colour in which the word was printed. A fixation point appeared in the centre of the screen for one second followed by the first word. When the participant responded to the stimulus the second word appeared on the screen, which was preceded by a fixation point. This procedure was repeated until responses for all trials in each block had been given. The heroin group responded to three counterbalanced blocks of 24 heroin-related and 24 neutral words. The alcohol group responded to three counterbalanced blocks of 24 alcohol-related and 24 neutral words. The cigarette smokers responded to three counterbalanced blocks of 24 smoking-related and 24 neutral words. In counterbalanced order, controls received one block of each of the substance-related word blocks ( 24 heroin-related and 24 neutral, 24 alcohol-related and 24 neutral and 24 smoking-related and 24 neutral).

A DNA cheek swab kit was used to collect the data for genetic testing. The 48 base pairs (bp) repeat in exon 3 of the dopamine D4 receptor gene (DRD4) was genotyped using PCR. This region was amplified using primers D4-1 (5'GGT CTG CGG TGG AGT CTG - 3') and D4-2 (5' - GCG ACT ACG TGG TCT ACT - 3'). The PCR reaction was performed in a $20 \mu 1$ volume containing $100 \mathrm{ng}$ genomic template, 10pmol of each primer (D4-1 and D4-2) and 200 $\mu \mathrm{mol} / 1$ of each dNTP (ATP, CTP, TTP, $50 \%$ DEAZA GTD, $50 \%$ GTP). Taq polymerase was used in Perkin Elmer buffer with $1.5 \mathrm{mls} \mathrm{MgCl}_{2}$ and $10 \%$ DMSO. After an initial denaturation of 10 minutes at $95^{\circ} \mathrm{C}$, the Taq polymerase was added followed by a cycle of $95^{\circ} \mathrm{C}$ for one minute, annealing at $55^{\circ} \mathrm{C}$ for one minute and extension at $72^{\circ} \mathrm{C}$ for one minute then 33 cycles of amplification at $95^{\circ} \mathrm{C}$ and a final extension step of 10 minutes at $72^{\circ} \mathrm{C}$ performed in a PTC $200 \mathrm{MJ}$ Research DNA engine. These PCR conditions followed the standard method used in the laboratory that previously had been tried and tested and followed standard published procedures [31]. Fragments were resolved by $2 \%$ agarose gel electrophoresis and visualized by ethidium bromide staining and UV Tran illumination. Results were recorded using a Polaroid camera. Allelic and genotypic frequencies were calculated by direct counting of genotypes and alleles then independently verified by a specialist to ensure genotyping accuracy. DRD4 alleles vary in size from 332-706bp (2-10 repeats of a $48 \mathrm{bp}$ fragment). These were grouped into short (25 repeats) and long (6-10 repeats) alleles on the gene so that individual genotypes could be divided into homozygote 'long-long' and 'short-short' and heterozygote 'long-short'.

\section{RESULTS}

Mean correct Response Times (RT) in milliseconds (ms) on the emotional Stroop task were analysed using $2 \times 2$ ANOVA with stimulus type (substance-related versus neutral words) as the within participant factor and DRD4 allele (long versus short) as the between participant factor (for mean RT see Table 1). ANOVA was performed to examine whether presence or absence of the long allele at the DRD4 gene differentiated participants with respect to their Stroop performance.

Heroin abusers on average made 1.8 errors (SD 4.4) on the Stroop task. These participants may have delayed their responses to ensure accuracy during the task as a significant correlation was found between error rate and mean RT $(\mathrm{r}=$ $0.45, \mathrm{n}=80, \mathrm{p}<0.01$, two-tailed). The majority $(76.8 \%)$ of participants reached ceiling effects. There was a significant 
interaction between stimulus type and genotype $(\mathrm{F}[1,72]=$ $4.76, \mathrm{p}=0.03)$. Planned comparisons t-tests indicated that heroin abusers with the long allele at DRD4 spent significantly longer to respond to the heroin-related words than they did to the neutral words when compared to participants without the long allele $(\mathrm{t}[1,72]=2.47, \mathrm{p}=0.01)$.

Table 1. Long and Short Allele Groups Mean Stroop RT (ms) on Stimulus Type

\begin{tabular}{|c|c|c|c|c|c|c|}
\hline \multirow{2}{*}{ Heroin Users } & \multicolumn{2}{|c|}{ Long } & \multicolumn{2}{|c|}{ Short } & \multicolumn{2}{|c|}{ Total } \\
\hline & Mean & $S D$ & Mean & $S D$ & Mean & $S D$ \\
\hline Heroin & 1103 & 431 & 922 & 283 & 955 & 321 \\
\hline Neutral & 938 & 184 & 869 & 218 & 882 & 213 \\
\hline Interference & 165 & & 53 & & 73 & \\
\hline $\mathrm{N}$ & 19 & & 56 & & 75 & \\
\hline \multirow{2}{*}{ Smokers } & \multicolumn{2}{|c|}{ Long } & \multicolumn{2}{|c|}{ Short } & \multicolumn{2}{|c|}{ Total } \\
\hline & Mean & $S D$ & Mean & $S D$ & Mean & $S D$ \\
\hline Smoking & 1035 & 362 & 844 & 151 & 940 & 203 \\
\hline Neutral & 956 & 285 & 834 & 278 & 890 & 281 \\
\hline Interference & 79 & & 10 & & 50 & \\
\hline $\mathrm{N}$ & 15 & & 60 & & 75 & \\
\hline \multirow{2}{*}{ Alcoholics } & \multicolumn{2}{|c|}{ Long } & \multicolumn{2}{|c|}{ Short } & \multicolumn{2}{|c|}{ Total } \\
\hline & Mean & $S D$ & Mean & $S D$ & Mean & $S D$ \\
\hline Alcohol & 1044 & 290 & 967 & 346 & 976 & 340 \\
\hline Neutral & 973 & 227 & 943 & 347 & 947 & 336 \\
\hline Interference & 71 & & 24 & & 29 & \\
\hline $\mathrm{N}$ & 14 & & 56 & & 70 & \\
\hline \multirow{2}{*}{ Controls } & \multicolumn{2}{|c|}{ Long } & \multicolumn{2}{|c|}{ Short } & \multicolumn{2}{|c|}{ Total } \\
\hline & Mean & $S D$ & Mean & $S D$ & Mean & $S D$ \\
\hline Substance & 900 & 374 & 820 & 145 & 824 & 162 \\
\hline Neutral & 925 & 359 & 831 & 173 & 840 & 185 \\
\hline Interference & 25 & & 11 & & 16 & \\
\hline $\mathrm{N}$ & 4 & & 67 & & 71 & \\
\hline
\end{tabular}

Smokers made on average 1.8 errors (SD 4.3). It would appear that participants did not delay their responses to ensure accuracy during the task because no significant correlation was found between error rate and mean RT $(\mathrm{r}=0.06, \mathrm{n}$ $=80, \mathrm{p}=0.59$, two-tailed) and the majority (92\%) of participants reached ceiling effects. ANOVA was performed to examine whether presence or absence of the long allele at the DRD4 gene differentiated participants with respect to their responses to smoking-related stimuli. There was a significant interaction between stimulus type and genotype $(\mathrm{F}[1,72]=$ $4.66, \mathrm{p}=0.03)$. Planned comparisons t-tests indicated that individuals with the long allele at DRD4 spent significantly longer to respond to the smoking-related words than they did to the neutral words when compared to participants without the long allele $(\mathrm{t}[1,72]=3.79, \mathrm{p}=<0.01)$.
Alcoholics made on average 1.5 errors (SD 2.7). Correlational analysis indicated that participants did not delay their responses to ensure accuracy during the task $(\mathrm{r}=0.13, \mathrm{n}=$ $80, \mathrm{p}=0.27$, two-tailed) and $94.8 \%$ of participants reached ceiling effects. Presence or absence of the long allele at the DRD4 gene did not differentiate alcoholics with respect to their Stroop performance as there was no main effect of genotype $(\mathrm{F}[1,68]=0.34, \mathrm{p}=0.56)$ and the within participant effect for stimulus type was not significant $(\mathrm{F}[1,68]=$ $2.14, \mathrm{p}=0.15$ ) although a trend to delay can be observed in the alcoholics carrying the long variant (see mean RT in Table 1).

Controls made on average 1.6 errors (SD 2.4). Correlational analysis indicated that controls did not delay their responses to ensure accuracy during the task $(r=0.01, n=80$, $\mathrm{p}=0.96$, two-tailed) and $91.2 \%$ reached ceiling effects. Presence or absence of the long allele at the DRD4 gene did not differentiate controls with respect to their Stroop performance as there was no main effect of genotype ( $F[1,69]$ $=1.02, \mathrm{p}=032)$ and the within participant effect for stimulus type was not significant $(\mathrm{F}[1,69]=0.59, \mathrm{p}=044)$.

\section{CONCLUSIONS}

The DRD4 gene polymorphism was found to influence attentional bias in heroin users and cigarette smokers. Both groups spent significantly longer to respond to substancerelated stimuli if participants carried the long allele at the DRD4 gene, whereas participants without the long allele did not show this difference. This processing bias makes the suppression of meaning of substance-related words more difficult and leads to greater interference during the task. Substance abusers appear to be preoccupied with stimuli that are related to their drug so therefore spend longer to respond to the colour in which the word is printed. This finding is in line with previous research $[2,7]$ that has found the DRD4 gene to moderate cue-elicited craving in smokers. However, it does not support a positive finding conducted with alcohol dependent participants [5]. Reasons for this discrepancy between findings could be difficult to identify because "given the current state of knowledge regarding the functional significance of the DRD4 and the biological action of alcohol, the precise nature of the interaction between the DRD4 VNTR polymorphism and alcohol is not clear." [p.143] [5].

It could be argued that these conflicting findings are a result of the differing populations, measures and methods used in the studies. The present study used a Stroop task to measure attentional bias to alcohol-related cues, whereas previous work [6] has used alcoholic and non-alcoholic beverages as cues to elicit craving for alcohol and self-report measures of attention.

Alternatively, failure to identify a significant association between the DRD4 gene polymorphism and reactivity to alcohol-related cues in the present study could be due to the relative importance of this particular gene on alcohol dependence. Previous studies have reported associations with the DRD4 gene long allele and heroin [32-36] and nicotine [37-39] but not alcohol [40-42] dependence. In the present study, mean reaction times recorded for alcohol abusers did show a trend in the same direction as that of drug abusers however this trend did not reach statistical significance. Therefore, the trend that can be seen from the findings re- 
ported here appears consistent in that the DRD4 gene polymorphism has a greater influence on drug dependence than it has on alcohol dependence, with other genes, such as the aldehyde dehydrogenase (ALDH2) gene possibly having a greater effect on alcohol [43].

Further work, examining the relative importance of other genes on attentional bias, is necessary to clarify this issue. Nevertheless, the long allele at the DRD4 gene may represent a genetic mechanism that influences the expression of incentive salience of both heroin and nicotine. Theoretically, these findings can be explained from the view of the incentive sensitisation theory [24]. Craving is elicited by cues whereby related stimuli have the ability to direct behaviour toward drug seeking. This being the case, there are implications for the treatment of substance dependence. A fuller understanding of individual susceptibility to sensitisation and the mechanisms that underlie attentional bias could lead to some improvement in the effectiveness of treatment by focusing on the long-term urge to use drugs that arises from a sensitised brain system that mediates their motivation to use.

In conclusion, the present study found that the DRD4 VNTR polymorphism is associated with attentional bias to substance-related cues using an emotional Stroop task. More research is necessary to be carried out to determine whether this finding is replicable and the extent to which other genes might influence such attentional biases.

\section{ACKNOWLEDGEMENTS}

The authors would like to thank all individuals who took part in the study, which was funded by London Metropolitan University and the Society for the Study of Addiction. We would especially like to thank Jon Mill for his help with laboratory procedures. We would also like to thank the Oaks resource centre; the Addaction day program; the Woodcote group practice; Spitalfields practice; the Drug Dependency Unit at St. Clements hospital and the Social, Genetic and Developmental Psychiatry Research Centre, Institute of Psychiatry.

\section{REFERENCES}

[1] Van den Wildenberg E, Janssen RG, Hutchison KE, van Breukelen GJ, Wiers RW. Polymorphisms of the dopamine D4 receptor gene (DRD4 VNTR) and cannabinoid CB1 receptor gene (CNR1) are not strongly related to cue-reactivity after alcohol exposure. Addict Biol 2007; 12: 210-20.

[2] Hutchison KE, LaChance H, Niaura R, Bryan A, Smolen A. The DRD4 VNTR polymorphism influences reactivity to smoking cues. J Abn Psychol 2002; 111(1): 134-43.

[3] Lusher JM, Chandler C, Ball D. Dopamine D4 Receptor gene (DRD4) is associated with Novelty Seeking (NS) and substance abuse: The saga continues... Mol Psychiatry 2001; 6: 497-9.

[4] Feldpausch DL, Needham LM, Stone MP, et al. The role of dopamine D4 receptor in the induction of behavioural sensitisation to amphetamine and accompanying biochemical and molecular adaptations. J Pharmacol Exp Ther 1998; 286: 497-508.

[5] Schoffelmeer AN, DeVries TJ, Wardeh G, van de Ven HW, Vanderschuren LJ. Psychostimulant-induced behavioural sensitisation depends on nicotinic receptor activation. J Neurosci 2002; 22(8): 3269-76.

[6] Hutchison KE, McGeary J, Smolen A, Swift R, Bryan A. The DRD4 VNTR polymorphism moderates craving after alcohol consumption. Health Psychol 2002; 2: 139-46.

[7] Shao C, Li Y, Jiang K, Zhang D, Xu Y, Lin L. Dopamine D4 receptor polymorphism modulates cue-elicited heroin craving in Chinese participants. Psychopharmacology 2006; 186: 185-90.
[8] Berridge KC, Robinson TE. Parsing reward. Trends Neurosci 2003; 26: $507-13$.

[9] Cloninger CR, Pryzbeck TR, Svrakic DM, Neurogenetic adaptive mechanisms in alcoholism. Science 1987; 236: 410-6.

[10] Salamone JD, Correa M, Mingote SM, Weber SM. Beyond the reward hypothesis: alternative functions of nucleus accumbens dopamine. Curr Opin Pharmacol 2005; 5: 34-41.

[11] Dickinson A, Smith J, Mirenowicz J. Dissociation of Pavlovian and instrumental incentive learning under dopamine antagonists. Behav Neurosci 2000; 114: 468-83.

[12] Wyvell CL, Berridge KC. Intra-accumbens amphetamine increases the conditioned incentive salience of sucrose reward: enhancement of reward "wanting" without enhanced "liking" or response reinforcement. J Neurosci 2000; 20: 8122-30.

[13] Wyvell CL, Berridge KC. Incentive sensitisation by previous amphetamine exposure: increased cue-triggered "wanting" for sucrose reward. J Neurosci 2001; 21: 7831-40.

[14] De Borchgrave R, Rawlins JNP, Dickinson A, Belleine BW. Effects of cytotoxic nucleus accumbens lesions on instrumental conditioning in rats. Exp Brain Res 2002; 144: 50-68.

[15] Niaura RS, Rohsenow DJ, Binkoff JA, Monti PM, Pedraza M, Abrams DB. Relevance of cue reactivity to understanding alcohol and smoking relapse. J Abnorm Psychol 1988; 97: 133-52.

[16] Stroop JR. Studies of interference in serial verbal reactions. J Exp Psychol 1935; 18: 643-65.

[17] Williams JM, Mathews A, MacLeod C. The emotional Stroop task and psychopathology. Psychol Bull 1996; 120(1): 3-24.

[18] Gross TM, Jarvik ME, Rosenblatt MR. Nicotine abstinence produces content-specific Stroop interference. Psychopharmacology 1993; 110: 333-6.

[19] Johnsen BH, Thayer JF, Laberg JC, Asbjornsen AE. Attentional bias in active smokers, abstinent smokers and nonsmokers. Addict Behav 1997; 22: 813-7.

[20] Waters AJ, Feyerabend C. Determinants and effects of attentional bias in smokers. Psychol Addict Behav 2000; 14(2): 110-20.

[21] Stormark KJ, Laberg JC, Nordby H, Hugdahl K. Alcoholics' selective attention to alcohol stimuli: Automated processing? J Stud Alcohol 2000; 61: 18-23.

[22] Stetter F, Ackerman K, Bizer A, Straube ER, Mann K. Effects of disease related cues in alcoholic inpatients: Results of a controlled 'alcohol Stroop' study. Alcohol Clin Exp Res 1995; 19: 3: 593-9.

[23] Bauer D, Cox WM. Alcohol-related words are distracting to both alcohol abusers and non-abusers in the Stroop colour-naming task. Addiction 1998; 93(10): 1539-42.

[24] Robinson TE, Berridge KC. The neural basis of drug craving: An incentive sensitisation theory of addiction. Brain Res Rev 1993; 18 : 247-91.

[25] Van Tol HHM, Bunzow JR, Guan HC, et al. Cloning of the gene for a human dopamine D4 receptor with high affinity for the antipsychotic clozapine. Nature 1991; 350: 610-4.

[26] Gossop M, Darke S, Griffiths P, et al. The Severity of Dependence Scale: psychometric properties of the SDS in English and Australian samples of heroin, cocaine and amphetamine users. Addiction 1995; 90: 607-14.

[27] Stockwell TR, Hodgson RJ, Taylor C, Rankin H. The development of a questionnaire to measure severity of alcohol dependence. Br J Addict 1979; 74: 79-87.

[28] Tiffany ST, Drobes DJ. The development and initial validation of a questionnaire on smoking urges. Br J Addict 1991; 86: 1467-76.

[29] Cox WM, Pothos EM, Johnsen B, Laberg J. Methodological issues attached to the alcohol Stroop paradigm: comments on an article by Sharma, Albery, and Cook (2001). Addiction 2001; 96: 1261-65.

[30] Sharma D, Albery IP, Cook C. Selective attentional bias to alcoholrelated stimuli in problem drinkers and non-problem drinkers. Addiction 2001; 96: 285-95.

[31] Rietschel M, Naber D, Oberlander H. Efficacy and side-effects of clozapine: testing for association with allelic variation in the dopamine D4 receptor gene. Neuropsychopharmacology 1996; 15: 4916.

[32] Kotler M, Cohen H, Segman R, et al. Excess dopamine D4 receptor (DRD4) exon III seven repeat allele in opioid dependent subjects. Mol Psychiatry 1997; 2: 251-4.

[33] Li T, Xu K, Deng H, et al. Association analysis of the dopamine D4 gene exon III VNTR and heroin abuse in Chinese subjects. Mol Psychiatry 1997; 2: 413-6. 
[34] Mel H, Horowitz R, Ohel N, et al. Additional evidence for an association between the dopamine D4 receptor (D4DR) exon III sevenrepeat allele and substance abuse in opioid dependent subjects: relationship of treatment retention to genotype and personality. Addict Biol 1998; 4: 473-81.

[35] Li T, Zhu ZH, Liu X, et al. Association analysis of polymorphisms in the DRD4 gene and heroin abuse in Chinese subjects. Am J Med Genet 2000; 96: 616-21.

[36] Lusher JM, Ebersole L, Ball D. Dopamine D4 Receptor gene and severity of dependence. Addict Biol 2000; 5: 469-72.

[37] Shields PG, Lerman C, Audrain J, et al. Dopamine D4 receptors and the risk of cigarette smoking in African-Americans and Caucasians. Cancer Epidemiol Biomarkers Prev 1998; 7: 453-8.

[38] Lerman C, Caporaso N, Main D, et al. Depression and selfmedication with nicotine: The modifying influence of the dopamine D4 receptor gene. Health Psychol 1998; 17: 56-62.
[39] Sabol SZ, Nelson ML, Fisher C, et al. A genetic association for cigarette smoking behaviour. Health Psychol 1999; 18(1): 7-13.

[40] Chang FM, Ko HC, Lu RB, Paktis AJ, Kidd KK. The dopamine D4 receptor gene (DRD4) is not associated with alcoholism in three Taiwanese populations: Six polymorphisms tested separately and as haplotypes. Biol Psychiatry 1997; 41: 394-405.

[41] Parsian A, Chakraverty S, Fisher L, Cloninger CR. No association between polymorphisms in the human dopamine D3 and D4 receptors genes and alcoholism. Am J Med Genet 1997; 74: 281-5.

[42] Roman T, Bau CHD, Almeida S, Hutz H. Lack of association of the dopamine D4 receptor gene polymorphism with alcoholism in a Brazilian population. Addict Biol 1999; 4: 03-7.

[43] Kreek MJ, Nielson DA, LaForge KS. Genes associated with addiction. Neuromol Med 2004; 5: 85-107.

(C) Lusher et al.; Licensee Bentham Open.

This is an open access article licensed under the terms of the Creative Commons Attribution Non-Commercial License (http://creativecommons.org/licenses/by$\mathrm{nc} / 3.0 /$ ) which permits unrestricted, non-commercial use, distribution and reproduction in any medium, provided the work is properly cited. 